\title{
Instruídas e trabalhadeiras Trabalho feminino no final do século $\mathrm{XX}^{*}$
}

\author{
Cristina Bruschini** \\ Maria Rosa Lombardi***
}

\begin{abstract}
Resumo
Com base em informações oficiais do IBGE/Instituto Brasileiro de Geografia e Estatística, do MTE/Ministério do Trabalho e Emprego $e$ do MEC/Ministério da Educação e Cultura, o texto mostra a consolidação do acesso das mulheres ao mercado de trabalho na década de noventa e sua manutenção no mercado informal $e$ formal, apesar das crises econômicas da década. Com ênfase na escolaridade, o artigo revela que a escolaridade feminina supera a masculina a partir do $2^{\circ}$ grau, as jovens concluem os cursos técnicos e profissionais, assim como o ensino médio, em maior número do que os rapazes e constituem cerca de $60 \%$ dos que cursam o superior. Contudo, as moças concentram-se em algumas áreas do conhecimento - artes, humanas, biológicas e saúde - que as qualificam para ocupar posteriormente, no mercado de trabalho, os chamados guetos profissionais femininos.
\end{abstract}

Palavras-chave: Mulheres, Mercado de Trabalho, Educação, Ensino Médio, Ensino Superior, Ocupações Profissionais,

Guetos Ocupacionais.

\footnotetext{
" Recebido para publicação em novembro de 2001.

** Pesquisadora da Fundação Carlos Chagas, São Paulo.

****Assistente de Pesquisa da Fundação Carlos Chagas, São Paulo.
} 
Instruídas e trabalhadeiras

Educated and Earnest Workers:

Women's Work at the End of the $20^{\text {th }}$ Century

\begin{abstract}
Based on official data provided by the IBGE (Brazilian Institute of Geography and Statistics), by the Ministry of Labor and Employment, and by the Ministry of Education and Culture, this text shows the consolidation of women's access to the labor market during the 90's. It also shows that their presence remained unchanged, both in the formal and in the informal market in spite of the economic crisis of that decade. Emphasizing the schooling level, the article reveals that after elementary school, girls tend to conclude technical and professional courses, as well as achieve high school degrees, in a higher number than boys. Young women account for $60 \%$ of college students. However, young girls concentrate their preference in some areas of knowledge such as Humanities, Social Sciences, Arts, Biological Sciences and Health. Therefore, they end up as skilled professionals in the so-called ghettos of female laborforce.
\end{abstract}

Key words: Women, Workforce, Education, High Scholl Degree, College Degree, Professional Occupations, Occupational Ghettos. 
Em textos anteriores sobre a participação das mulheres no mercado de trabalho brasileiro, demos especial destaque a várias tendências: em primeiro lugar, a intensidade e a constância do aumento da inserção de mulheres, sobretudo as mais velhas $e$ com responsabilidades familiares, no mercado de trabalho, em contraposição a uma força de trabalho que, até os anos setenta, se revelava jovem, solteira e sem filhos. ${ }^{1}$

Chamamos a atenção também para a má qualidade do trabalho realizado pelas mulheres, que, em grande parte, se concentra em atividades informais e precárias, ou seja, de má qualidade e não protegidas pela legislação. Por outro lado, também constatamos a ocorrência de tendências inovadoras, que apontam para a conquista, por parte de mulheres mais escolarizadas, de bons empregos, embora mantendo a concentração em guetos femininos, bem como desigualdades salariais entre trabalhadores de ambos os sexos, mesmo nos bons empregos.

1 BRusChINI, Cristina. Gênero e Trabalho no Brasil: novas conquistas ou persistência da discriminação? (Brasil, 1985-95). In: RocHA, Maria I. B. da. (org.) Trabalho e Gênero - Mudanças, permanências e desafios. Campinas-São Paulo/ Editora 34/ABEP/NEPO-UNICAMP/CEDEPLAR-UFMG, 2000, pp.13-18; A situação da mulher brasileira nas últimas décadas. In: VELLOSO, João P. R. (org.) Brasil 500 Anos - Futuro, presente e passado. Rio de Janeiro, José Olympio, 2000, pp.423-464; Brasil: la calidad del empleo de las mujeres. Continuidades y cambios. In: VALENZUELA, Maria E. e REINECKE, Gerhard. (eds.) ¿Más y Mejores Empleos para las Mujeres? Santiago, Chile, OIT/Oficina Internacional del Trabajo, 2000, pp.135-192; BRUSCHINI, Cristina e LOMBARDI, Maria R. A bipolaridade do trabalho feminino no Brasil contemporâneo. Cadernos de Pesquisa, n ${ }^{\circ} 110$, São Paulo/Campinas, Fundação Carlos Chagas/Autores Associados, julho de 2000, pp.67-104; O trabalho da mulher nos primeiros anos da década de noventa. Anais do X Encontro Nacional de Estudos Populacionais, ABEP/Associação Brasileira de Estudos Populacionais, 1996, pp.483-516; Mulheres e homens no mercado de trabalho brasileiro: um retrato dos anos noventa. Versão brasileira do livro Les Nouvelles frontières de l'inégalité Hommes et femmes sur le marché du travail, organizado por Margaret Maruani. São Paulo, Senac. [prelo] 
Instruídas e trabalhadeiras

Neste texto atualizamos essas informações até o final da década de noventa e apresentamos novos ângulos sobre a temática da participação no mercado de trabalho por sexo, como a inserção no sistema escolar médio e superior brasileiro, nos quais são adquiridas credenciais para as melhores ocupações. $\mathrm{O}$ texto baseia-se em informações oficiais do IBGE/Instituto Brasileiro de Geografia e Estatística, do MTE/Ministério do Trabalho e Emprego e do MEC/Ministério da Educação e Cultura. Todas as informações, extraídas diretamente das respectivas bases de dados $^{2}$, foram por nós analisadas e inseridas no Banco de Dados sobre o Trabalho das Mulheres, no site da Fundação Carlos Chagas $^{3}$, onde se encontram disponíveis para consulta, juntamente com uma gama muito mais ampla de dados.

\section{Indicadores de participação econômica por sexo}

Independentemente da especificidade de cada um de nossos textos anteriores, todos eles mostraram, em primeiro lugar, a continuidade do crescimento da população economicamente ativa feminina (PEA), desde os anos 70 até a metade da década de 90. Este aumento prossegue até o final da década, quando o contingente de mulheres na PEA atinge mais de 31 milhões de trabalhadoras. ${ }^{4}$ (tabela 1 )

\footnotetext{
2 No caso das informações do Ministério da Educação, obtivemos, mediante solicitação ao INEP/SEEC, tabelas especiais desagregadas por sexo e áreas do conhecimento. Agradecemos à $\mathrm{Dr}^{\mathrm{a}}$ Maria Helena Guimarães de Castro e à equipe do setor de disseminação do MEC/INEP, em especial à $\mathrm{Dr}^{\mathrm{a}}$ Maria das Dores Pereira Rosa, pelo pronto atendimento ao nosso pedido.

3 BruschinI, Cristina e LOMBARDI, Maria R. Banco de Dados sobre o Trabalho das Mulheres. Série Mulheres e Mercado Formal de Trabalho, Fundação Carlos Chagas [http://www.fcc.org.br], 1998.

4 Os conceitos referidos nesta e em outras tabelas são aqueles tradicionalmente utilizados pelo IBGE. O primeiro deles é População Economicamente Ativa (PEA), assim entendida a população de 10 anos e mais que, no período anterior da pesquisa, estava exercendo trabalho remunerado, estava trabalhando sem remuneração em algumas atividades, ou não estava trabalhando, mas procurava
} 
A taxa de atividade feminina, ao final da década, chega a mais de $47 \%$, ou seja, de cada 100 mulheres em idade de trabalhar, mais de 47 trabalhavam ou procuravam trabalho. O incremento acentuado ocorrido entre 90 e 93 deve ser atribuído em parte a uma redefinição do conceito de trabalho adotada pelo IBGE a partir 92. A nova definição do conceito passa a incluir atividades para o autoconsumo, a produção familiar e outras até então não consideradas como trabalho. Como essas atividades sempre foram realizadas, sobretudo, por mulheres, os efeitos dessa nova metodologia incidiram sobre elas, enquanto as taxas masculinas permaneceram inalteradas nesse período. ${ }^{5} \mathrm{~A}$ nova metodologia do IBGE, no entanto, ainda não avançou a ponto de incluir na PEA a atividade doméstica realizada pelas donas-decasa, que continua a ser classificada como inatividade econômica. Agora mais visíveis e em maior número, as trabalhadoras passam a representar, no final da década, uma parcela de cerca de $41 \%$ da força de trabalho brasileira.

As taxas masculinas mantêm patamares elevados, em torno de $75 \%$, com declínio no final da década, cuja marca, no que

trabalho. Portanto, segundo aquela fonte, fazem parte da PEA os Ocupados (trabalhando regularmente) e os desocupados, assim considerados os que não trabalhavam, mas tomaram alguma providência para encontrar trabalho. Às parcelas da população que não estavam trabalhando regularmente e não estavam em busca de trabalho, o IBGE denomina População NãoEconomicamente Ativa. Aqui se inserem as pessoas que, à época da pesquisa, exerciam afazeres domésticos, estudantes, aposentados e pensionistas, pessoas que viviam de rendas, detentos, doentes ou inválidos e pessoas sem ocupação. Por taxa de atividade entendemos o percentual de ativos/as (que estão na PEA), em relação aos que estão em idade ativa, ou seja, têm mais de 10 anos (PIA). Finalmente, o percentual na PEA diz respeito à parcela feminina ou masculina do contingente total de trabalhadores.

${ }^{5}$ Para uma discussão mais aprofundada sobre o tema da visibilidade do trabalho feminino, assim como sobre esta nova metodologia, ver BRUSCHINI, C. Gênero e Trabalho no Brasil... Op. cit.; e Fazendo as perguntas certas: como tornar visível a contribuição econômica das mulheres para a sociedade? In: ABRAMO, Laís; ABREU, Alice R. P. Gênero e trabalho na sociologia latinoamericana. São Paulo/Rio de Janeiro, ALAST, 1998, pp.277-294. 
Instruídas e trabalhadeiras

tange à participação por sexo no mercado de trabalho, é a consolidação da presença feminina.

\section{Trabalho das mulheres e características demográficas e familiares}

Em trabalhos anteriores mostramos que o significativo aumento da atividade das mulheres, uma das mais importantes transformações ocorridas no país desde os anos 70, teria resultado não apenas da necessidade econômica e das oportunidades oferecidas pelo mercado, em conjunturas específicas, mas também, em grande parte, das transformações demográficas, culturais e sociais que vem ocorrendo no país e que tem afetado as mulheres e as famílias brasileiras.

A intensa queda da fecundidade reduziu o número de filhos por mulher, sobretudo nas cidades $e$ nas regiões mais desenvolvidas do país, as famílias reduziram seu tamanho, aumentou o número de famílias chefiadas por mulheres. Transformações nos padrões culturais e nos valores relativos ao papel social da mulher, intensificadas pelo impacto dos movimentos feministas desde os anos setenta e pela presença cada vez mais atuante das mulheres nos espaços públicos, alteraram a constituição da identidade feminina, cada vez mais voltada para o trabalho produtivo. A expansão da escolaridade $e$ o ingresso nas universidades viabilizaram o acesso das mulheres a novas oportunidades de trabalho. A consolidação de tantas mudanças é um dos fatores que explicaria não apenas o crescimento da atividade feminina, mas também as transformações no perfil da força de trabalho desse sexo, processo que vem ocorrendo desde a década de oitenta. Na década de 90 tais transformações demográficas se consolidam, provocando a transformação da população brasileira e de suas famílias: a taxa de fecundidade caiu de 5,8 filhos, em 1970, para 2,3 filhos em 1999 e alteraram-se os padrões de mortalidade, ambos processos 
que modificam a distribuição etária da população em relação ao peso relativo da população infanto-juvenil e da população idosa.

Em relação às famílias, confirmam-se, no período analisado, tendências já detectadas na década de 80 , como a redução de seu tamanho $e$ o crescimento das chefiadas por mulheres. O número de famílias, no final da década, atinge mais de 46 milhões, o declínio dos níveis de fecundidade provoca redução no tamanho delas que, no final dos anos noventa, passam a ter apenas 3,4 membros. Finalmente, prossegue o aumento do percentual de famílias chefiadas por mulheres que, em 98 , chega a $26 \%$ do total das famílias brasileiras. Essas famílias estão mais bem representadas nos estratos mais pobres da população. Em 1998, $45 \%$ das chefes de família brasileiras eram pretas e pardas, e nessa mesma data, $14 \%$ tinham rendimentos inferiores a 1 salário mínimo. ${ }^{6}$

Na década analisada, não foi apenas o aumento que caracterizou a mão-de-obra feminina, mas também algumas significativas alterações em seu perfil. As trabalhadoras, que até o final dos anos setenta, em sua maioria, eram jovens, solteiras $e$ sem filhos, passaram a ser mais velhas, casadas e mães a partir dos anos oitenta. Na década seguinte, a atividade feminina também aumenta, principalmente nas faixas etárias mais elevadas. $\mathrm{Em} \mathrm{1998,} \mathrm{a} \mathrm{mais} \mathrm{alta} \mathrm{taxa} \mathrm{de} \mathrm{atividade,} \mathrm{superior} \mathrm{a} \mathrm{66 \% ,} \mathrm{é}$ encontrada entre mulheres de 30 a 39 anos e cerca de $63 \%$ das de 40 a 49 anos também são ativas (tabela 2). A expansão do terciário, ocorrida nessas duas décadas, teria sido favorável à inserção das mulheres dessas faixas etárias. Entretanto, com a recuperação da indústria nos anos seguintes, especialmente no começo de 2.000 , elas começam a perder espaço para as mais

${ }^{6}$ BRUSChINI, C. e LombardI, M. R. Banco de Dados sobre o Trabalho das Mulheres. Op. cit. 
Instruídas e trabalhadeiras

jovens ${ }^{7}$, numa demonstração da associação existente entre idade e inserção no mercado de trabalho, no caso das mulheres.

O envelhecimento da PEA feminina entre os anos 70 e 90, ao lado do expressivo aumento do trabalho das esposas (categorias cônjuges do IBGE), cuja atividade passou de $20 \%$ no início da década de oitenta para 51,3\% em 1998, sugere que as responsabilidades familiares não estariam mais constituindo um fator impeditivo ao trabalho feminino de mercado, como ocorria até os anos 70. (tabela 3)

Pode-se afirmar que, no âmbito da oferta de trabalhadoras, tem havido significativas mudanças. Restam, no entanto, algumas continuidades que dificultam a dedicação das mulheres ao trabalho ou fazem dela uma trabalhadora de segunda categoria, que está sempre em desvantagem no mercado. Em primeiro lugar, elas continuam sendo as principais responsáveis pelas atividades domésticas e cuidados com os filhos e demais familiares, o que representa uma sobrecarga para aquelas que também realizam atividades econômicas. Em segundo, a presença de filhos pequenos continua sendo um fator que dificulta a ocupação feminina. De fato, ao tomar como base as mulheres de 15 anos ou mais, que tiveram filhos e cujo último filho é vivo, constatamos, para 1998, que as taxas de atividade das mães são muito mais baixas quando os filhos tem menos de 2 anos (47\%), ou mesmo entre 2 e 4 anos (58\%), em comparação às taxas de mães de filhos maiores. As taxas de atividade das mães de filhos maiores de 4 anos giram entre $62 \%$ e $65 \% .^{8}$ (tabela 4 )

A maternidade é um dos fatores que mais interferem no trabalho feminino, quando os filhos são pequenos. A responsabilidade pela guarda, cuidado e educação dos filhos na família limita a saída da mulher para o trabalho remunerado,

7 Fundação SEADE/Sistema Estadual de Análise de Dados. Mulher e Trabalho em busca da eqüidade social. São Paulo, Fundação SEADE, $n^{\circ} 3$, março de 2001.

8 Bruschini, C. e Lombardi, M. R. Banco de Dados sobre o Trabalho das Mulheres. Op. cit. 
sobretudo se os rendimentos obtidos são insuficientes para cobrir custos com formas remuneradas de cuidado infantil. Contudo, quando a necessidade econômica é tão premente que inviabiliza o exercício da maternidade em tempo integral, como nas famílias muito pobres ou nas chefiadas por mulheres, outros arranjos, como a rede de parentesco, inclusive os filhos maiores, ou redes de vizinhança, poderão ser acionados para olhar as crianças enquanto a mãe vai trabalhar. Segundo pesquisa da Fundação SEADE, na cidade de São Paulo, em 1995, 30\% das meninas de 10 a 14 anos estudavam, cuidavam dos irmãos pequenos e ajudavam nas tarefas domésticas, em prejuízo de seu tempo de estudo e de lazer. ${ }^{9}$ A insuficiência de equipamentos coletivos como as creches, que atendem parcela muito pequena das crianças brasileiras, contribui para aumentar o peso da maternidade sobre as mulheres e, em particular, sobre as trabalhadoras. Mesmo quando trabalham fora, as mães continuam sendo as principais responsáveis pelo cuidado com as crianças pequenas. Segundo dados da Pesquisa Nacional sobre Demografia e Saúde, 23\% das trabalhadoras cuidam elas mesmas dos filhos menores de 5 anos, $34 \%$ são ajudadas por parentes e apenas $10,2 \%$ ficam em creches. ${ }^{10}$

O crescimento do trabalho das casadas e mães poderia ser tomado, de um lado, como um indício da pressão econômica, que estaria forçando mulheres com essas características a procurar o mercado de trabalho. A diversificação das pautas de consumo, gerando novas necessidades e desejos, o empobrecimento da classe média e a necessidade de arcar com os custos de educação e saúde, devido a precarização dos sistemas públicos de atendimento, fariam parte desse processo. Contudo, esse aumento

9 ID. Trabalho doméstico, um trabalho invisível. Informativo Mensal sobre a Mulher Paulista: Mulheres em Dados, São Paulo, Fundação SEADE, $n^{\circ} 8$, outubro de 1997.

${ }^{10}$ BemFam/Sociedade Civil Bem-Estar Familiar no Brasil. Pesquisa Nacional sobre Demografia e Saúde/PNDS - 1996. Rio de Janeiro, UNFA/UNICEF/BEMFAM, 1997, p.37. 
Instruídas e trabalhadeiras

também é fruto de um intenso processo de modernização e de mudança cultural observados no Brasil a partir dos anos setenta, do qual faz parte a expansão da escolaridade, à qual as mulheres vêm tendo cada vez mais acesso, como comentamos a seguir.

\section{Escolaridade das mulheres e das trabalhadoras}

Como demonstram dados para 1999, as mulheres têm nível de instrução mais elevado do que os homens, na população em geral. Até a conclusão do ensino fundamental (8 anos de estudo), a igualdade de gênero pode ser observada, mas a partir do ensino médio (9 a 11 anos de estudo) o predomínio das mulheres sobre os homens, em termos de escolaridade, passa a se impor e prossegue a seguir. Como se verifica na tabela 5 , mais de $55 \%$ do alunado do $2^{\circ}$ grau é do sexo feminino e entre os que têm nível de instrução mais elevado esse percentual é de 54,2\%.

Esses dados do IBGE são corroborados por outros do Ministério da Educação, segundo os quais, na mesma data, 55,1\% das matrículas no ensino médio eram femininas. Além disso, no total de concluintes desse nível de ensino, o percentual feminino, em 99, sobe para 58,5\%. ${ }^{11}$ Ou seja, as mulheres representam parcela superior à dos homens entre os estudantes do ensino médio, mas esta parcela é ainda mais representativa entre os que permanecem mais na escola e concluem este nível de ensino. Esta constatação já foi feita em outros estudos, como o de Rosemberg, para as décadas de 70 e 80 . Esta autora sugere como explicação para esse achado fatores intra e extra-escolares. Em primeiro lugar, as alunas do $1^{\circ}$ grau obtêm melhores resultados escolares do que os alunos e suas taxas de evasão e repetência são mais baixas do que as deles, o que as leva em maior número ao nível seguinte de estudo. Em segundo, a cultura escolar vigente em sociedades patriarcais como a brasileira exigiria das meninas, e não dos

${ }^{11} \mathrm{MEC} / \mathrm{INEP}$. Censo Educacional. Brasília, MEC/INEP [http://www.inep.gov.br], junho de 2001. 
meninos, atitudes de dedicação aos estudos, obediência e bom comportamento, favoráveis à permanência na escola e prosseguimento dos estudos. ${ }^{12}$ Além disso, a escola seria um espaço de sociabilidade mais atraente às jovens do que aos jovens. ${ }^{13}$

Fora da escola, pressões sociais e econômicas mais amplas provocariam o ingresso mais precoce dos rapazes no mercado de trabalho, em trabalhos incompatíveis com a continuidade dos estudos - em que pese a maior oferta de cursos noturnos juvenis na década ${ }^{14}$ - em contraposição às moças, que se dedicariam mais ao trabalho doméstico, passível de conciliação com os estudos.

No ensino superior, as mulheres, que já eram quase $60 \%$ dos concluintes em 1990, ampliaram sua presença na década, atingindo percentual superior a $61 \%$ em 97 . Constituem maioria também - 55,1\% - entre aqueles que ingressaram no ensino superior, pelo vestibular de $1998 .{ }^{15}$ (tabela 6)

Não pairam dúvidas, portanto, sobre o avanço das mulheres na aquisição de escolaridade, o que lhes propicia maiores credenciais para seu ingresso e permanência no mercado de trabalho em ocupações que requerem estudo. Uma análise dos percentuais femininos por áreas do conhecimento, no entanto, revela que, tanto no ensino técnico e profissional quanto no nível superior de ensino persistem determinados guetos femininos que se reproduzem, posteriormente, no mercado de trabalho. No

\footnotetext{
${ }^{12}$ Rosemberg, Fúlvia. $2^{\circ}$ Grau no Brasil: cobertura, clientela e recursos. Cadernos de Pesquisa, nº 68, São Paulo, Cortez, fevereiro de 1989, pp.39-54.

${ }^{13}$ Ver MADEIRA, Felícia R. A trajetória das meninas dos setores populares: escola, trabalho... ou reclusão. In: MADEIRA, Felícia R. (org.) Quem mandou nascer mulher? Estudos sobre crianças e adolescentes pobres no Brasil. Rio de Janeiro, Record/Rosa dos Tempos, 1997, pp.45-134.

${ }^{14}$ IBGE. Síntese de Indicadores Sociais. Rio de Janeiro, IBGE, 2000.

${ }^{15}$ MEC/INEP. Censo da Educação Superior. Brasília, MEC/INEP, junho de 2001, tabelas especiais desagregadas por sexo, para áreas do conhecimento. [http://www.inep.gov.br]
} 
Instruídas e trabalhadeiras

ensino técnico e profissional, por exemplo, as concluintes de 99 predominam no ensino tecnológico da área de Serviços, como turismo e saúde, e em cursos técnicos de imagem pessoal, artes e saúde, também na área de Serviços. ${ }^{16}$ No ensino superior, os percentuais femininos mais elevados encontram-se nas áreas de lingüística, letras e artes (83\%), nas ciências humanas (82\%), nas ciências biológicas (74\%) e nas ciências da saúde (67,6\%). Na década analisada, essas duas últimas áreas tiveram aumento expressivo de participação feminina, sendo aquelas nas quais se deu o maior incremento da presença de moças. Ainda que em menor número, as mulheres são também maioria nas ciências exatas e da terra, área na qual sua participação, porém, sofreu declínio na década. Em contrapartida, sua presença ultrapassou a masculina nas ciências sociais aplicadas, área do conhecimento que abriga uma extensa e diversificada gama de cursos, alguns deles tradicionais redutos femininos - biblioteconomia, economia doméstica e serviço social, por ex. -, outros, cursos preparatórios para áreas profissionais nas quais as mulheres estão ingressando de forma significativa desde a década de oitenta: administração, arquitetura/urbanismo e direito. Mesmo na engenharia/tecnologia, tradicional reduto masculino, o aumento da participação feminina foi relevante. $\mathrm{O}$ mesmo se pode dizer das ciências agrárias, área do conhecimento na qual as mulheres ocupavam pouco mais de $1 / 4$ das vagas em 90 .

Informações sobre a parcela feminina entre os que ingressaram nas universidades pelo vestibular de 98 revelam persistência de guetos - lingüística, letras e artes, ciências humanas, biológicas e ciências da saúde -, aumento da presença feminina em algumas áreas, como ciências agrárias, ou ainda o declínio em algumas, como ciências exatas e da terra e engenharia $e$ tecnologia, que havia tido aumento entre as formandas do ano anterior. Essas observações nos permitem levantar a hipótese de

${ }^{16}$ MEC/INEP. Censo da Educação Profissional. Brasília, MEC/INEP, junho de 2001. [http://www.inep.gov.br] 
que a sexualização das ocupações ${ }^{17}$ é um processo que se forma ainda nos bancos escolares, com efeitos perversos sobre a inserção feminina posterior no mercado de trabalho. Confirmando essa tese, pesquisas recentes vêm demonstrando que a ruptura de guetos pelas mulheres no sistema educacional tem efeitos benéficos em sua inserção profissional. Este é o caso da pesquisa de Cristina Teodoro, que entrevistou alunas e egressas de cursos técnicos de engenharia de escolas do SENAI e constatou a maior facilidade que tiveram, em relação a jovens de áreas tipicamente femininas, para obter estágios e conseguir bons empregos depois de formadas. ${ }^{18}$

$\mathrm{O}$ diferencial de gênero constatado na escolaridade brasileira tem impacto na população economicamente ativa, pois as trabalhadoras têm níveis de escolaridade mais elevados do que seus colegas. Segundo dados do IBGE, a média de anos de estudo da PEA, em 1999, era de 6,3 anos. No entanto, enquanto a PEA feminina tinha 6,8 anos de estudo, a masculina não passava de 5,9. ${ }^{19}$ No período analisado, aumenta a escolaridade dos trabalhadores de ambos os sexos, porém o aumento da escolaridade da PEA feminina é mais significativo. Como é possível constatar na tabela 7 , em $98,29,2 \%$ das trabalhadoras tinham 11 ou mais anos de estudo, o que se verificava para apenas $20,2 \%$ dos trabalhadores.

O impacto da escolaridade sobre o trabalho feminino se expressa nas taxas mais elevadas de atividade entre aquelas com mais instrução. Em 93, enquanto a taxa feminina de atividade era de $47 \%$, a das mulheres com 15 anos ou mais de estudo era superior a $81 \%$, ou seja, de cada 100 mulheres com nível superior,

\footnotetext{
${ }^{17}$ Sobre os temas da sexualização das ocupações e guetos profissionais, ver BRUSCHINI, Cristina. Sexualização das ocupações: o caso brasileiro. Cadernos de Pesquisa. São Paulo, Fundação Carlos Chagas, 1979.

${ }^{18}$ TEODORO, Cristina. Mulheres na contramão da segregação ocupacional. Dissertação de mestrado, Pontifícia Universidade Católica de São Paulo, abril de 2001.

${ }^{19}$ IBGE. Síntese de Indicadores Sociais. Rio de Janeiro, IBGE, 2000.
} 
Instruídas e trabalhadeiras

81 eram ativas no começo da década. No final dela persiste a mesma tendência, com aumento também da atividade das que tem de 11 a 14 anos de instrução, cuja taxa de atividade atinge $70 \%$.

A elevada escolaridade feminina tem tido efeitos expressivos em sua colocação no setor formal do mercado de trabalho, onde se encontram os empregos protegidos por lei, no setor privado $e$ no público da economia. Segundo dados do Ministério do Trabalho $^{20}$ apresentados na tabela 8, mais da metade (55\%) dos empregos desse setor eram ocupados, em 98, por empregados com ensino fundamental completo ( $8^{\text {a }}$ Série), pouco mais de $29 \%$ com $2^{\circ}$ grau e $15,3 \%$ com nível superior. Na mesma data, porém, enquanto mais de $60 \%$ do emprego masculino se concentrava no primeiro nível de escolaridade (até a $8^{\mathrm{a}}$ Série), o feminino predominava nos níveis mais elevados de instrução, $2^{\circ}$ grau (38\%) e superior (21\%), comprovando que a escolaridade feminina é mais elevada do que a masculina no segmento formalizado do mercado de trabalho.

É verdade que, nesta parcela da economia, o número de empregos ocupados por mulheres, embora tenha crescido, em números absolutos, mais do que aqueles ocupados por homens, ainda é relativamente pequeno, se comparado ao total. Em 98, apenas $38,4 \%$ dos registros de emprego formalizado eram do sexo feminino. Entretanto, nos empregos de escolaridade mais elevada, as mulheres predominavam: mais da metade $(53 \%)$ daqueles de nível superior completo de instrução eram ocupados por elas naquele segmento da economia, na mesma data. Além disso, no espaço de 10 anos, não apenas a parcela de empregos femininos nesse segmento regulamentado da economia se ampliou (de $34 \%$

${ }^{20}$ Esses dados são provenientes do Anuário RAIS - Relação Anual de Informações Sociais -, que contém informações fornecidas pelas empresas, referentes a registros de emprego, remuneração, em associação com outras variáveis, entre as quais sexo, idade e escolaridade. Trata-se de uma fonte de dados declarados anualmente pelos empregadores e refere-se apenas ao segmento formal do mercado de trabalho. 
em 88 , para $38 \%$ em 98), mas também o predomínio de empregos de nível de instrução média e superior ocupados por mulheres se intensificou.

A expansão dos níveis de escolaridade observados no setor formal da economia brasileira, tanto para o emprego feminino quanto para o masculino, como se expressa na tabela 8, poderia ser interpretada tanto como resultado da expansão da escolaridade de $2^{\circ}$ e $3^{\circ}$ graus no país, como também pela maior exigência dos empregadores, principalmente os das médias e grandes empresas, em relação aos níveis de instrução de seus contratados.

O predomínio de empregos femininos nos níveis mais elevados, por sua vez, poderia ser explicado por duas razões: em primeiro lugar, porque a escolaridade das mulheres é mais elevada na população em geral e na PEA, em segundo, porque o setor formal inclui os estatutários, ou seja, os empregos no funcionalismo público, no qual as mulheres predominam, principalmente nas áreas da saúde e educação, e que em sua maioria requerem, pelo menos, níveis médios de instrução.

\section{O lugar das mulheres no mercado de trabalho}

No que tange à ocupação da mão-de-obra brasileira na década de $90^{21}$, os dados das PNADs sinalizam para a persistência dos já conhecidos padrões diferenciados de inserção feminina $e$ masculina segundo setores ou grupos de atividades econômicas: pela ordem, os setores do mercado de trabalho nos quais as trabalhadoras continuam encontrando maiores oportunidades de trabalho e emprego são a prestação de serviços, a agropecuária, a

\footnotetext{
${ }^{21}$ No conceito de ocupação utilizado pelo IBGE incluem-se as pessoas que tinham trabalho na semana de referência da pesquisa e aquelas que não exerceram o trabalho remunerado por motivo de férias, licença, greve, etc.
} 
Instruídas e trabalhadeiras

extração vegetal e a pesca, o setor social ${ }^{22}$, o comércio de mercadorias e a indústria. Por seu lado, a força de trabalho masculina manteve presença significativa, também pela ordem, na indústria, nos trabalhos ligados à agropecuária, extração vegetal $e$ pesca, no comércio de mercadorias e na prestação de serviços. (tabela 9)

Mesmo que esses padrões estruturais da ocupação feminina e masculina não tenham se alterado na década, vale ressaltar que podem ser verificadas oscilações conjunturais devidas às instabilidades econômicas e políticas ocorridas nos anos analisados. Particularmente no que se refere ao peso da indústria na ocupação masculina, ela absorvia $29 \%$ dos homens em 1990, caiu para 27\% e 26\%, respectivamente em 1993 e 1995 e teve ligeira recuperação em 1998. A mesma tendência - queda nos primeiros anos da década, uma certa estabilização em patamares inferiores em meados dos noventa e ligeira recuperação em 1998 se observa para a ocupação feminina em quase todos os setores econômicos. $\mathrm{Na}$ indústria, por exemplo, de $14 \%$ em 1990, ela passa para $10 \%$ em $93,9 \%$ em 95 e se recupera ligeiramente em 98. O setor Social, por sua vez, responsável por $19 \%$ da ocupação feminina em 90, passa para 16\% em 93 e 95, terminando em $18 \%$ em 98. Nos serviços, setor com forte presença de mulheres, estavam ocupadas $31 \%$ delas em 90 , decrescendo para $28,5 \%$ em 93, voltando a subir para $30 \%$ em 95 e encerrando o período em $29 \%$. No que tange à ocupação masculina nesse último setor, ainda que tenha se mantido em taxas em torno de $10 \%$ na década, deve-se notar a persistência de uma tendência de lento aumento de participação que vem sendo registrada há cerca de três décadas: se em 1970 ele correspondia a apenas 5\% da ocupação masculina, passa a fazê-lo na ordem de $10 \%$ em 90 ,

${ }^{22}$ São considerados como integrantes do Setor Social, conforme definição do IBGE, os Serviços comunitários e sociais, os Serviços médicos, odontológicos e veterinários e o Ensino. 
fechando a década em $12 \% .^{23}$ Como os serviços são tradicionalmente reduto feminino por excelência, algumas hipóteses podem ser levantadas para explicar esse movimento, particularmente a partir da segunda metade dos anos 80. Estaria havendo um certo deslocamento das mulheres do setor, pressionadas pela entrada dos homens expulsos da atividade industrial. ${ }^{24}$ Esse movimento teria como causas basicamente os processos de reestruturação produtiva e organizacional das empresas, a retração dos negócios frente às sucessivas instabilidades econômicas e frente à acirrada competição internacional proporcionada pela abertura da economia brasileira a partir de 90 , bem como a tendência à diminuição da importância do setor secundário da economia em favor de um terciário ampliado e diversificado, conhecida como terciarização. Essa conjuntura os teria estimulado a adentrar em atividades de prestação de serviços, grande parte delas operando na informalidade.

Analisando a posição na ocupação dos brasileiros denominação atribuída pelo IBGE aos variados tipos de vínculos de trabalho que se estabelecem no mercado -, nota-se que é ligeiramente declinante a parcela de homens na categoria empregados, a qual inclui os com carteira de trabalho assinada pelo empregador e os sem ela. Essa tendência, que perdura até 1998, tem início nos primeiros anos da década e pode ser considerada como reflexo do cenário recessivo que ocorreu a partir de 1990 e de modificações estruturais pelas quais vem passando a economia brasileira em seu movimento de ajuste tecnológico. (tabela 10)

${ }^{23}$ Dados constantes de tabela do Banco de Dados sobre o Trabalho das Mulheres. Série O Lugar das Mulheres no Mercado de Trabalho e Setores de Atividade. [http//www.fcc.org.br].

${ }^{24}$ BRUSCHINI, Cristina. Brasil: la calidad del empleo de las mujeres. Continuidades y cambios. In: ValenzUela, M. E.; ReineCKE, G. (eds.) ¿Más y Mejores Empleos para las Mujeres? Op. cit. 
Instruídas e trabalhadeiras

Note-se que a inserção das mulheres no mercado de trabalho brasileiro tem sido caracterizada através do tempo pela marca da precariedade que tem atingido uma importante parcela de trabalhadoras. Mesmo que os dados sinalizem para um decréscimo relativo desse contingente na década de 90, ainda assim, em 1998 nada menos que 36\% da força de trabalho feminina ou 10 milhões de mulheres situavam-se em nichos precários do mercado de trabalho, seja como trabalhadoras domésticas, seja realizando atividades não remuneradas ou trabalhos destinados ao consumo próprio ou do grupo familiar. $\mathrm{O}$ desfavorecimento dessa colocação feminina fica ainda mais patente quando é confrontada com os homens: em 98 apenas $10 \%$ deles se encontravam naquelas situações. ${ }^{25}$ (tabela 11)

O trabalho doméstico, nicho ocupacional feminino por excelência, no qual mais de $90 \%$ dos trabalhadores são mulheres, manteve-se como importante fonte de ocupação, praticamente estável na década, absorvendo $17 \%$ da força de trabalho. Como revelou nosso estudo sobre o tema ${ }^{26}$, esse percentual vem diminuindo no tempo, uma vez que, em 1970, o emprego doméstico absorvia mais de $1 / 4$ da mão-de-obra feminina. Essa ocupação, no entanto, ainda representa oportunidade de colocação para mais de quatro milhões de mulheres no mercado de trabalho brasileiro e é considerada precária em função das longas jornadas de trabalho desenvolvidas pela maioria das

\footnotetext{
${ }^{25}$ Apesar de não ser este o local para uma discussão mais aprofundada sobre a questão do segmento informal do mercado de trabalho, no qual se situariam os nichos mais precários, vale remarcar que os estudos preocupados com essa questão têm apresentado resultados diversos no que se refere à dimensão desse segmento, devido à aplicação de metodologias diferentes. O IBGE, por exemplo, através da PME/Pesquisa Mensal de Emprego, estima que no final dos anos 90 a metade dos ocupados nas principais regiões metropolitanas do país trabalhava informalmente. Sobre a questão, ver JAKOBSEN, K., MARTINS, R., DOMBROWSKI, O. (orgs.) Mapa do Trabalho Informal: perfil socioeconômico dos trabalhadores informais na cidade de São Paulo. Coleção Brasil Urgente, São Paulo, CUTCentral Única dos Trabalhadores/Fundação Perseu Abramo, 2000.

${ }^{26}$ BRUSCHINI, C. e LOMBARDI, M. A bipolaridade do trabalho feminino... Op. cit.
} 
trabalhadoras, pelo baixo índice de posse de carteira de trabalho $e$ pelos baixos rendimentos auferidos. Nosso estudo mostrou que, em 97, 47\% das empregadas domésticas trabalhavam mais de 45 horas por semana, $28 \%$ delas por mais de 49 horas. Além disso, em 1998, 76\% delas não possuíam carteira de trabalho e $88 \%$ ganhavam até dois salários-mínimos.

Outras formas de ocupação precárias - o trabalho não remunerado e aquele executado para o consumo próprio ou da unidade familiar e que são desenvolvidos majoritariamente por mulheres - também se mostraram, em termos relativos, decrescentes no período analisado. Se $13,5 \%$ das mulheres ocupadas trabalhavam sem remuneração em 93, em 98 elas passaram a significar $11 \%$. Da mesma forma, $10 \%$ delas trabalhavam para consumo ou construção próprios ou para o núcleo familiar mais próximo em 93 e $8 \%$ em $98 .^{27}$ Ressalte-se que é no setor agrícola, principalmente, que o trabalho sem remuneração e para o próprio consumo são realizados, no primeiro caso pelas muito jovens (mais de 67\% com até 19 anos) e no segundo, pelas mais idosas (37\% com mais de 60 anos). ${ }^{28} \mathrm{O}$ não pagamento pelo trabalho desenvolvido pelas mulheres, contudo, também está presente no comércio $(15 \%)$ e nos serviços (9\%), muito provavelmente em negócios de pequeno porte e de caráter familiar.

Os dados sinalizam também um ligeiro aumento na forma de ocupação por conta-própria para ambos os sexos, tipo de vínculo mais característico do setor Serviços e do Comércio, refúgio de sobrevivência de muitos expulsos dos setores mais formalizados e organizados do mercado de trabalho. (tabela 10)

\footnotetext{
${ }^{27}$ Ressalte-se que as categorias "trabalhadores domésticos", "trabalhadores para consumo próprio ou do núcleo familiar" surgem nas PNADs a partir de 1992. A primeira delas, desagregada dos "empregados" e a última, dos "nãoremunerados". O refinamento da classificação, portanto, permite a melhor visualização da ocupação feminina, apesar de trazer problemas à análise das séries longitudinais referentes ao trabalho das mulheres.

${ }^{28}$ BRUSCHINI, C. Gênero e Trabalho no Brasil... Op. cit., pp.13-18.
} 
Instruídas e trabalhadeiras

Referendam esta interpretação os resultados da pesquisa "Economia Informal Urbana", realizada em 1997 pelo IBGE em todos os municípios urbanos do país, a qual apontou que as micro-empresas informais no Brasil desenvolviam atividades preponderantemente no comércio e nos serviços de reparação, pessoais, domiciliares e de diversão. O motivo que levou quase um terço desses proprietários a iniciarem seus empreendimentos foi o desemprego; o rendimento auferido, porém, foi o estímulo para nele persistir. A pesquisa revelou também que, como trabalhadores por conta-própria, ganhavam em média $\mathrm{R} \$ 400,00$ e como pequenos empregadores cerca de $\mathrm{R} \$ 1.000,00$; no mercado formal, a média de remuneração para seu nível de instrução chegaria, no máximo, a dois salários-mínimos. ${ }^{29}$ Outro estudo, desta feita abordando trabalhadores no setor informal - no qual se incluem, além dos proprietários de pequenas unidades produtivas com até cinco empregados e trabalhadores a ela vinculados, todos os trabalhadores sem carteira, autônomos, empregados domésticos e trabalhadores familiares - na região metropolitana de São Paulo, no ano de 1998, apresenta caracterização dos ocupados assemelhada: o motivo que levou as pessoas à informalidade foi o desemprego; elas apresentavam baixo nível de escolaridade, trabalhavam na prestação de serviços e no comércio $e$ auferiam rendimentos, em geral, inferiores a três salários mínimos. ${ }^{30}$

\footnotetext{
${ }^{29} \mathrm{~A}$ pesquisa em questão considerou como pertencentes ao setor informal as unidades de propriedade de trabalhadores por conta própria e de empregadores com até 5 empregados, bem como os trabalhadores nessas unidades produtivas, moradores de áreas urbanas, com produção em pequena escala, destinadas a gerar emprego e renda aos envolvidos. Maiores informações sobre a pesquisa "ECINF/Economia Informal Urbana" podem ser encontradas no site http//www.ibge.gov.br.

30 Jakobsen, K., Martins, R., Dombrowski, O. (orgs.) Mapa do Trabalho Informal... Op. cit.
} 
Cristina Bruschini, Maria Rosa Lombardi

\section{Ocupações femininas e masculinas}

A estrutura ocupacional masculina e feminina pode ser desvendada com maior detalhe, permitindo uma visão mais clara dos nichos profissionais segundo o sexo do trabalhador, a partir da análise dos dados referentes ao mercado de trabalho formal. ${ }^{31}$

A tabela 12 mostra que os diversos ramos industriais, responsáveis pela absorção da mão-de-obra masculina em uma variada gama de ocupações típicas de cada um deles e em ocupações transversais como operadores de máquinas, movimentadores de mercadorias e cargas, diminuíram sua importância no período analisado, seguindo a própria dinâmica desse setor, cuja retração foi recorde nos anos 90 . Ainda assim, no final da década, a indústria continuava importante fonte de oferta de emprego para os homens, uma vez que cerca de $38 \%$ dos empregos masculinos provinham das atividades industriais. $\mathrm{O}$ setor de serviços era responsável pela absorção de $31 \%$ dos homens, dos quais $17 \%$ em serviços administrativos e $14 \%$ em serviços de turismo, serventia segurança e saúde.

Enfocando a estrutura ocupacional feminina, nota-se que ela se caracteriza, de modo geral, por dois segmentos diferenciados em termos de qualificação, prestígio e consequentemente, remuneração. De um lado, aquelas ocupações, que, grosso modo, teriam menos prestígio $e$ ofereceriam menor remuneração, como as ocupações em serviços administrativos e em serviços de turismo, serventia, higiene e beleza e auxílio à saúde. Elas representam $50 \%$ dos empregos femininos com carteira assinada. De outro, as ocupações de nível superior nas áreas jurídica, do ensino e das artes, responsáveis pela oferta de $18 \%$ dos empregos femininos.

Analisando em profundidade, no $\mathrm{CBO} /$ Cadastro Brasileiro de Ocupações, cada um desses grandes agregados de ocupações, vemos que o Grande Grupo Trabalhadores em serviços

${ }^{31}$ A fonte de dados citada é a RAIS. 
Instruídas e trabalhadeiras

administrativos $e$ assemelhados, o maior empregador das mulheres $^{32}$, engloba internamente uma gama bastante ampla de Famílias Ocupacionais, a maior parte delas referentes a ocupações de apoio administrativo e algumas de nível intermediário de chefia, quais sejam: chefes intermediários, administrativos, de contabilidade e de finanças; agentes de administração de empresas públicas e privadas; secretários, datilógrafos, estenógrafos; trabalhadores de serviços de contabilidade e caixas; operadores de máquinas contábeis, de calcular e de processamento automático de dados; chefes de serviço de transporte e comunicações; despachantes, fiscais e cobradores de transportes coletivos; classificadores de correspondência, carteiros, mensageiros; telefonistas, telegrafistas. Nele se incluem, portanto, algumas funções que têm sido tradicionalmente exercidas quase que exclusivamente por mulheres, como secretárias, telefonistas, recepcionistas e outras. Em 1998, por exemplo, 87\% dos secretários, $85 \%$ dos telefonistas e $83 \%$ dos recepcionistas, $67 \%$ dos auxiliares de escritório e caixas, $65 \%$ dos arquivistas e $60 \%$ dos agentes administrativos eram mulheres. No caso das três primeiras ocupações citadas as proporções são muito assemelhadas às registradas no ano de 1988, indicando a persistência de um padrão de feminização. Para as demais ocupações, as proporções aumentaram significativamente entre 1988 e 1998, sinalizando na mesma direção.

\footnotetext{
${ }^{32}$ As nomenclaturas Grande Grupo de Ocupações e Família Ocupacional são utilizadas na Classificação Brasileira de Ocupações/CBO e correspondem a níveis de agregação das ocupações. "O Grande Grupo de Ocupações é a classificação mais agregada; reúne grandes áreas de emprego mais do que tipos específicos de trabalho... A Família Ocupacional ou Grupo de Base reúne ocupações que apresentam estreito parentesco, tanto em relação à natureza do trabalho, quanto aos níveis de qualificação exigidos." Ministério do Trabalho e Emprego, Secretaria de Políticas de Emprego e Salário, CBO/Classificação Brasileira de Ocupações, Brasília, 1994, p.12.
} 
No que se refere ao Grande Grupo das ocupações dos serviços de turismo, hospedagem, embelezamento, segurança, auxiliares de saúde, etc. (20\% dos empregos) verifica-se que, com exceção dos gerentes de hotéis, restaurantes e bares, que exercem funções de nível de supervisão, os demais profissionais são executores de serviços especializados. São eles os mordomos e governantes, os cozinheiros, garçons e barmen, os trabalhadores de serventia e comissários de serviços de transporte de passageiros, os trabalhadores de serviços de administração, conservação, manutenção e limpeza de edifícios e logradouros públicos, os lavadeiros e tintureiros e os trabalhadores em serviços de higiene e embelezamento, de proteção e segurança. Exemplos de ocupações tradicionalmente desempenhadas por mulheres aqui inclusas são: cabeleireiros (em $98,80 \%$ dos postos de trabalho eram femininos), governantas e mordomos ( $72 \%$ eram mulheres), lavadeiras e tintureiras (71\%), trabalhadores de serventia em domicílios e hotéis - arrumadeiras, camareiras, etc. - (70\%), comissárias de bordo (67\%), trabalhadores em serviços de conservação e limpeza de edifícios (58\%).

Por sua vez, o outro lado da ocupação feminina, representado pelas profissões de nível superior, de maior prestígio, nas áreas do ensino, das leis e das artes compõe-se das famílias ocupacionais juristas, professores, escritores, jornalistas, escultores, pintores e músicos, técnicos desportivos, etc.

O ensino se caracterizou através do tempo como uma das poucas áreas de atuação feminina qualificada no mercado de trabalho. Em que pesem as profundas modificações nas condições de trabalho e na remuneração dos docentes brasileiros nas últimas décadas, o que tem conduzido a uma desvalorização da função de ensinar por parte dos próprios professores e da sociedade (ou talvez por isso mesmo), a categoria continua eminentemente feminina: se em 1998, 95\% dos professores do ensino pré-escolar eram mulheres, assim como $88 \%$ dos professores do ensino especial, $87 \%$ dos professores do $1^{\circ}$ Grau, $72 \%$ dos de $2^{\circ}$ Grau, 
Instruídas e trabalhadeiras

$72 \%$ dos professores de língua e literatura do $3^{\circ}$ Grau, uma década antes as proporções eram muito próximas.

Mas as mulheres têm adentrado algumas áreas profissionais de prestígio reservadas para os homens até há bem pouco tempo atrás. Um exemplo desse movimento vem ocorrendo entre as profissões da área jurídica. Ainda que os postos de trabalho para esses profissionais tenham pequena significação numérica no conjunto dos empregos de ambos os sexos, o que importa aqui é a crescente participação feminina nesses nichos, ampliando as possibilidades de uma inserção qualificada no mercado de trabalho, pelo menos para aquelas mulheres mais escolarizadas: se em 1988 a RAIS registrava que a parcela feminina entre os advogados era de 31\%, em 98 ela atinge 40\%. Entre os procuradores, as mulheres representavam 36\% em 1988 e $43 \%$ em 1998.

Estudo por nós realizado com dados de 1996, que enfocou mulheres em algumas carreiras de prestígio - medicina, advocacia, arquitetura $^{33}$ - revelou que o ingresso das mulheres nessas áreas teria se dado pela convergência de vários fatores. De um lado, a intensa transformação cultural ocorrida a partir dos anos 60 , que impulsionou as mulheres para as universidades $e$ a expansão das vagas de $3^{\circ}$ Grau que atendeu a esse anseio feminino; de outro, as transformações pelas quais passaram essas profissões, em direção à especialização $e$ ao assalariamento, em detrimento da antiga autonomia profissional, o que repercutiu no nível de prestígio atribuído a esses profissionais, abrindo outras possibilidades para a inserção feminina além dos espaços tradicionalmente ocupados por elas como o magistério e a enfermagem. O perfil das profissionais analisadas no referido estudo se diferencia daquele dos seus colegas do sexo masculino apenas em relação à idade, pois, por adentrarem a profissão mais recentemente, elas são mais

${ }^{33}$ BRUSCHINI, Cristina e LOMBARDI, Maria R. Médicas, arquitetas, advogadas e engenheiras: mulheres em carreiras de prestígio. Revista Estudos Feministas, vol. 7, nos 1 e 2, Santa Catarina, UFSC, 1999, pp.9-24; e A bipolaridade do trabalho feminino no Brasil contemporâneo. Op. cit. 
jovens do que eles. No tocante ao trabalho propriamente dito, homens e mulheres se igualam em termos de jornadas de trabalho semanal e mantém vínculos de trabalho em proporções semelhantes aos setores público e privado. No entanto, mesmo que essas mulheres estejam ocupando novos e promissores espaços de trabalho, nos quais as características da sua inserção são bastante similares às dos homens, elas permanecem submetidas a uma desigualdade de gênero presente em todos os escalóes do mercado de trabalho no que tange aos rendimentos: ganham menos do que seus colegas de profissão do sexo masculino.

\section{Diferenciais de rendimentos por sexo}

A distribuição dos rendimentos de brasileiros e brasileiras na década de 90 denota os baixos níveis de ganhos da população como um todo e das mulheres em particular. Em 1998, 39\% dos ocupados e $47 \%$ das ocupadas recebiam até dois salários-mínimos (SM) mensais pelos trabalhos que desempenhavam, dentre os quais, respectivamente $18 \%$ e $26 \%$ recebiam até um saláriomínimo (tabela 13). No decorrer da década em análise, as variações na distribuição dos rendimentos refletem movimentos conjunturais de ordem econômica. Como mostra a tabela, 40\% dos ocupados em 1990 e 39\% em 98 recebiam até 2 SM. As proporções referentes às ocupadas para o mesmo patamar de rendimentos são, respectivamente, $53 \%$ e $47 \%$.

Mulheres ganhando menos do que os homens é uma situação recorrente não só no Brasil, mas em todo o mundo. Segundo a OIT/Organização Internacional do Trabalho, para o período 1991-1996, no Brasil, o rendimento recebido pelas mulheres em trabalhos não agrícolas correspondia a $72 \%$ daquele recebido pelos homens; na França o ganho feminino equivalia a $81 \%$ do masculino e no Japão a $62 \%{ }^{34}$

${ }^{34}$ OIT. Yearbook of Labour Statistics, 1996. 
Instruídas e trabalhadeiras

Se na distribuição dos rendimentos dos trabalhadores e das trabalhadoras brasileiras considerarmos também a influência da raça/cor, poderá se perceber, em primeiro lugar a situação desfavorável dos trabalhadores da raça negra no mercado de trabalho $e$, em segundo, a posição duplamente desfavorável das mulheres negras. Num contínuo decrescente de rendimentos, os homens brancos vêm em primeiro lugar, seguidos das mulheres brancas, dos homens negros e, finalmente, das mulheres negras. Dados de $1999^{35}$ revelaram que na região metropolitana de Salvador - onde $81 \%$ da população economicamente ativa é negra - ganham mais de cinco salários mínimos, $45 \%$ dos brancos, $32 \%$ das brancas, $19 \%$ dos negros e $9 \%$ das negras. Na região metropolitana de São Paulo, 51\% dos homens brancos ganhavam mais de $5 \mathrm{SM}, 34 \%$ das mulheres brancas e apenas $28 \%$ dos homens negros e $10 \%$ das mulheres negras. Naturalmente esse posicionamento subordinado no mercado de trabalho, que só pode ser revelado com maior clareza através de estudos mais aprofundados, tem raízes históricas e é fruto da convergência de vários fatores, por exemplo, a discriminação racial e de gênero, as diferentes inserções sócio-econômicas que engendram diversas oportunidades de acesso à riqueza, à educação, à cultura, etc. O posicionamento de homens e mulheres, brancos e negros, no mercado de trabalho reflete essas relações sociais pré-existentes. Estudo qualitativo desenvolvido junto a gerentes e sindicalistas dos ramos químico e automobilístico - ambos tradicionais na região do $\mathrm{ABC}$ paulista -, voltado para a identificação de dificuldades interpostas a negros e mulheres no local de trabalho, mostrou, de um lado, a tendência à concentração de mão-de-obra branca e masculina nos postos de trabalho mais qualificados, de maior responsabilidade e autoridade e de melhor remuneração -

${ }^{35}$ INSPIR/Instituto Sindical Interamericano pela Igualdade Racial, AFL$\mathrm{CIO} /$ Centro de Solidariedade, DIEESE/Departamento Intersindical de Estatística e Estudos Sócio-econômicos. Mapa da População Negra no Mercado de Trabalho - Regiões Metropolitanas de São Paulo, Salvador, Recife, Belo Horizonte, Porto Alegre e Distrito Federal, outubro de 1999. 
como gerentes, engenheiros, técnicos e supervisores -; de outro, a maior presença de mulheres brancas e negras e homens negros no chão-de-fábrica, em atividades de produção. Sinalizou também para o fato da desigualdade de raça tender a ser maior que a de gênero, uma vez que, mesmo que de forma tímida, vem aumentando nos últimos anos da década de 90 a presença de mulheres brancas nos dois primeiros escalóes de comando das fábricas (gerentes e engenheiros), o que não tem se verificado para homens negros e mulheres negras. ${ }^{36}$

As mais baixas remunerações recebidas pelas mulheres quando comparadas à dos homens são reafirmadas quando se consideram os setores econômicos, os grupos de horas trabalhadas e os anos de estudo. (tabela 14)

Por exemplo, em 1998, na indústria, onde as relações de trabalho são mais formalizadas, enquanto $37 \%$ dos ocupados recebiam até $2 \mathrm{SM}$, entre as ocupadas $49 \%$ se situavam na mesma faixa de renda. Na prestação de serviços, setor que mais emprega mulheres, $76 \%$ delas ganhavam até $2 \mathrm{SM}$ e apenas $41 \%$ dos ocupados; no setor Social, outro nicho ocupacional feminino, no qual se incluem as atividades de ensino e de auxílio à saúde, $41 \%$ das mulheres que ali trabalham e $26 \%$ dos homens situavam-se naquele patamar de rendimentos. A situação subordinada da mulher no mercado de trabalho se revela também pela expressiva proporção das trabalhadoras na agricultura que não auferem rendimento, $-81 \%$, enquanto $30 \%$ dos homens que trabalham nesse setor o fazem sem rendimentos. Em relação a 1995, de modo geral, a tendência observada foi de ligeira melhora na distribuição de rendimentos para ambos os sexos, diminuindo em

${ }^{36}$ FAPESP/Fundação de Amparo à Pesquisa em Ciências Sociais, CEBRAP/Centro Brasileiro de Análise e Planejamento, PMSA/Prefeitura Municipal de Santo André, CEERT/Centro de Estudos das Relações de Trabalho e Desigualdades, ELAS/Elizabeth Lobo Assessoria. Trabalho e Políticas Públicas: Gestão Local, Empregabilidade e Eqüidade de Gênero e Raça: um experimento de política Pública na região do $\mathrm{ABC}$ paulista. Relatório Substantivo Fase 1, São Paulo, junho de 2000, CD ROM, pp.87-125. 
Instruídas e trabalhadeiras

quase todos os setores econômicos a parcela de ocupados que auferiam rendimentos até $2 \mathrm{SM}$ e aumentando, proporcionalmente aquela da faixa subseqüente, mais de 2 a $5 \mathrm{SM}$.

No que tange à remuneração segundo os grupos de horas trabalhadas por semana, mais uma vez se constata que as mulheres sempre ganham menos que os homens, mesmo quando trabalham jornada semelhante. Considerando o período integral de 40 a 44 horas semanais -, temos $44 \%$ das mulheres ganhando até $2 \mathrm{SM}$ e $38 \%$ dos homens. Comparativamente a 1993, porém, o ano de 1998 mostra uma melhora na distribuição dos rendimentos para os trabalhadores e as trabalhadoras de período integral, pois em 93, 48\% dos ocupados e $56 \%$ das ocupadas recebiam até 2 SM pelo seu trabalho por aquela jornada semanal.

Finalmente, o rendimento segundo anos de estudo reforça ainda uma vez a discriminação salarial sofrida pelas mulheres no mercado de trabalho, apesar de o nível de escolaridade feminina ser mais elevado que o masculino. Entre os mais escolarizados de ambos os sexos, por exemplo, aquela discriminação parece ainda mais evidente: na faixa de 15 anos e mais de estudo, $85 \%$ dos homens e apenas $67 \%$ das mulheres ganhavam mais de $5 \mathrm{SM}$ em 98.

Comparativamente a 1993, o ano de 98 indica a acentuação da importância da escolaridade do(a) trabalhador(a) na possibilidade de auferir rendimentos do trabalho. Assim, se no primeiro ano $77 \%$ dos homens com 15 anos e mais de estudo recebiam mais de $5 \mathrm{SM}$, em 98 a proporção encontrada é de $85 \%$. Outra tendência é a diminuição da desigualdade de rendas entre os sexos para um mesmo patamar de escolaridade: em 93, 77\% dos homens e $51 \%$ das mulheres com 15 anos e mais de estudo ganhavam mais de $5 \mathrm{SM}$ (diferença de 26 pontos percentuais); em 98, os índices foram $85 \%$ e $67 \%$ (ou diferença de 18\%).

Esses dados nos levam a sugerir que, analisando o comportamento dos rendimentos do trabalho segundo o sexo, duas tendências parecem ter se consolidado nos anos 90. A primeira delas se refere ao conjunto dos trabalhadores brasileiros, 
sem diferenciação segundo o sexo e sinaliza um decréscimo da parcela de homens $e$ mulheres que auferem os mais baixos rendimentos (até $2 \mathrm{SM}$ ) pelo seu trabalho. A segunda tendência refere-se à desigualdade da remuneração entre os sexos no mercado de trabalho, resultado da valorização diversa atribuída ao trabalho dos homens e das mulheres. Os dados analisados mostraram a diminuição daquele espaço de desigualdade. Dito de outra forma, nos anos 90, as mulheres continuaram a ganhar menos que os homens independente do setor de atividade econômica em que trabalham, do tamanho da sua jornada de trabalho, do número de anos de estudo ou da sua posição na ocupação, mas as diferenças entre os seus ganhos e os masculinos diminuíram. ${ }^{37}$

\section{À guisa de conclusão}

Ao concluir este breve retrato sobre o trabalho de homens $e$ mulheres no Brasil, na década de noventa, é possível retomar alguns dos pontos discutidos e enfatizar alguns resultados. Em primeiro lugar, o texto mostra a consolidação do acesso das mulheres ao mercado de trabalho na década de noventa e sua manutenção no mercado de trabalho, apesar das crises econômicas da década. O texto mostra, ainda, a persistência de um perfil de mão-de-obra feminina - trabalhadoras mais velhas, casadas, com filhos -, que vinha se forjando desde os anos oitenta $e$ prosseguiu nos noventa, em associação a uma maior inserção feminina no setor terciário da economia. A consolidação de transformações demográficas marcantes na sociedade brasileira, que já vinham se anunciando em anos anteriores, tais como a queda da fecundidade, o envelhecimento da população, a redução do tamanho das famílias, o aumento do percentual de

${ }^{37}$ De fato, essa tendência também tem sido observada por outros estudiosos. Ver GUIMARÃES, Nadya A. Laboriosas, mas redundantes: gênero e mobilidade no trabalho no Brasil dos anos 90. Revista Estudos Feministas, Santa Catarina, CPH/CCE/UFSC, vol. 9, n 1, 2001. 
Instruídas e trabalhadeiras

famílias chefiadas por mulheres, é também retomada no artigo, mas este se detém, sobretudo, sobre o impacto da escolaridade na vida das mulheres e no trabalho feminino no mercado global e no formal. $\mathrm{O}$ artigo revela que a escolaridade feminina ultrapassa a masculina a partir do $2^{\circ}$ grau, as jovens concluem os cursos técnicos e profissionais, assim como o ensino médio, em maior número do que os rapazes e constituem cerca de $60 \%$ dos que cursam o ensino superior. Contudo, as moças concentram-se em algumas áreas do conhecimento - artes, humanas, biológicas e saúde - em que pese algumas outras aberturas. Ora, essa guetização, que pode ser constatada também no ensino técnico e profissional, as qualifica para ocupar os chamados guetos profissionais femininos no mercado de trabalho, ocupações com elevado contingente de mulheres que, devido a essa característica de gênero, detém menor prestígio e níveis mais baixos de remuneração. Tomemos como exemplo a área da saúde, em cujos cursos de nível superior mais cresceu a presença de mulheres na década de 90. Nela estão incluídos tanto os cursos mais tradicionais de medicina, enfermagem e odontologia, como inúmeros outros - educação física, fisioterapia, fonoaudiologia, nutrição, ortótica, psicomotricidade, terapia ocupacional, entre outros - que atraem mais as estudantes do que os estudantes, provocando a formação de novos guetos femininos ou a reprodução de velhos nichos de trabalho de mulheres. Num movimento circular, as mulheres dão preferência a fazer seus estudos em áreas do conhecimento que as preparam para ocupações nas quais suas chances de colocação no mercado de trabalho são elevadas. $\mathrm{Na}$ área em questão - a saúde - mais de $70 \%$ dos empregos do setor formal eram ocupados por mulheres, em 1998.

Em relação à estrutura do emprego, o artigo revela, reiterando o que tem sido dito em outros estudos, a diminuição do emprego formal urbano, resultado do grande enxugamento de postos de trabalho industriais, mais significativos no Sudeste. Entretanto, a análise de gênero empreendida neste texto mostrou 
que, nessa redução, os homens foram mais penalizados do que as mulheres. No segmento precário, no qual se concentram $36 \%$ das trabalhadoras $e$ as atividades menos protegidas do mercado emprego doméstico, atividades não-remuneradas, consumo próprio e familiar - as informações disponíveis nos levam a supor alguma melhora, em termos relativos. Em primeiro lugar, porque esse segmento não aumentou na década; em segundo porque, no emprego doméstico, o maior dos nichos femininos precários, diminui a proporção de trabalhadoras que recebem salários muito baixos, assim como aumentam os índices de registro em carteira dessa categoria.

Finalmente, no que se refere à distribuição dos salários, pudemos constatar nos dados analisados uma tendência geral, para homens e mulheres, de deslocamento das faixas salariais mais baixas para as intermediárias. O mais importante, no entanto, foi a constatação da ocorrência de uma redução da desigualdade salarial entre homens e mulheres, que pode ter sido provocada tanto pela flexibilização das atividades industriais, que atingiu especialmente os homens, quanto pelo ingresso maciço das mulheres em ocupações mais qualificadas e mais bem remuneradas em relação ao mercado de trabalho como um todo. 
Instruídas e trabalhadeiras

Tabelas

Tabela 1

Mulheres e homens no mercado de trabalho: indicadores de participação econômica - Brasil

\begin{tabular}{l|r|r|r}
\hline \hline Sexo e datas & $\begin{array}{c}\text { PEA } \\
\text { (Milhões) }\end{array}$ & $\begin{array}{c}\text { Taxas de } \\
\text { atividade }\end{array}$ & $\begin{array}{c}\text { Porcentagem } \\
\text { na PEA }\end{array}$ \\
\hline \hline Mulheres & & & \\
1990 & 22,9 & 39,2 & 35,5 \\
1993 & 28,1 & 47,0 & 39,6 \\
1995 & 30,0 & 48,1 & 40,4 \\
1998 & 31,3 & 47,6 & 40,7 \\
\hline Homens & & & \\
1990 & 41,6 & 75,3 & 64,5 \\
1993 & 42,9 & 76,0 & 60,4 \\
1995 & 44,2 & 75,3 & 59,6 \\
1998 & 45,6 & 73,6 & 59,3 \\
\hline \hline
\end{tabular}

Tabela 2

Taxas de atividades femininas segundo faixas de idade

\begin{tabular}{l|r|r|r|r}
\hline \hline \multicolumn{1}{c|}{ Faixas de idade } & 1970 & 1980 & 1990 & 1998 \\
\hline \hline 10 a 14 anos & 6,5 & 8,4 & 10,6 & 11,4 \\
15 a 19 anos & 23,6 & 31,3 & 41,4 & 41,6 \\
20 a 24 anos & 27,7 & 38,5 & 52,9 & 61,6 \\
25 a 29 anos & 23,1 & 36,3 & 52,7 & 64,5 \\
30 a 39 anos & 20,1 & 35,1 & 54,7 & 66,4 \\
40 a 49 anos & 19,5 & 30,7 & 49,5 & 62,6 \\
50 a 59 anos & 15,4 & 21,5 & 34,5 & 46,6 \\
60 anos e mais & 7,9 & 7,5 & 11,5 & 19,1 \\
Total & 18,2 & 26,6 & 39,2 & 47,5 \\
\hline \hline
\end{tabular}

Fonte: UNICEF/IBGE, FIBGE/Censo e PNADs. 
Cristina Bruschini, Maria Rosa Lombardi

Tabela 3

Taxa de atividade feminina segundo posição na família Brasil

\begin{tabular}{l|c|c|c}
\hline \hline Condição na familia & 1980 & 1990 & 1998 \\
\hline \hline Chefes & 43,3 & 51,2 & 56,4 \\
Cônjuges & 20,0 & 37,6 & 51,3 \\
Filhos & 27,3 & 36,2 & 38,2 \\
Outros & 23,3 & 28,1 & 32,2 \\
Sem parentesco & 74,9 & 80,0 & 77,7 \\
Total & 26,5 & 39,2 & 47,5 \\
\hline \hline
\end{tabular}

Fonte: FIBGE, Censo e PNADs.

Tabela 4

Taxas de atividade das mulheres que tiveram filhos, segundo faixa etária do último filho vivo*

Brasil, 1998

\begin{tabular}{l|c}
\hline \hline Idade do último filho vivo & $\begin{array}{c}\text { Taxas de atividade } \\
\mathbf{\%}\end{array}$ \\
\hline \hline até 2 anos & 47,1 \\
mais de 2 a 4 anos & 57,9 \\
mais de 4 a 5 anos & 61,8 \\
mais de 5 a 6 anos & 65,0 \\
mais de 6 a 7 anos & 63,7 \\
mais de 7 a 14 anos & 65,2 \\
mais de 14 anos & 40,1 \\
Total & 48,3 \\
\hline \hline
\end{tabular}

Fonte: FIBGE, PNAD/CD ROM

* foram consideradas as mulheres com 15 anos e mais que tiveram filhos e que têm vivo o último filho. 
Instruídas e trabalhadeiras

Tabela 5

Escolaridade das pessoas de 10 anos e mais e parcela feminina por nível de instrução - Brasil, 1999

\begin{tabular}{l|r|r|r}
\hline \hline \multirow{2}{*}{ Nível de instrução } & \multicolumn{2}{|c|}{ Distribuição } & \multirow{2}{*}{$\begin{array}{c}\text { \% de } \\
\text { mulheres }\end{array}$} \\
\cline { 2 - 3 } & Homens & Mulheres & \\
\hline \hline s/ instrução e menos de 1 ano & 13,6 & 13,2 & 51,0 \\
de 1 a 4 anos de estudo & 34,4 & 32,1 & 49,9 \\
de 5 a 8 anos de estudo & 28,4 & 27,6 & 50,8 \\
de 9 a 11 anos de estudo & 16,4 & 19,1 & 55,3 \\
12 anos de estudo e mais & 6,8 & 7,5 & 54,2 \\
não determinado/sem & 0,5 & 0,5 & - \\
declaração & & & \\
Total \% & 100,0 & 100,0 & 51,6 \\
Milhões & 63.019 .733 & 67.076 .057 & - \\
\hline \hline
\end{tabular}

Fonte: FIBGE, PNAD.

Tabela 6

Parcela feminina entre os concluintes do ensino superior em 1990 e 1997 e entre os ingressantes pelo vestibular em 1998, por áreas do conhecimento

\begin{tabular}{l|c|c|c}
\hline \multirow{2}{*}{ Áreas do conhecimento } & \multicolumn{2}{|c|}{ Concluintes } & $\begin{array}{c}\text { Ingresso } \\
\text { Vestibular }\end{array}$ \\
\cline { 2 - 3 } & 1990 & 1997 & 1998 \\
\hline \hline Brasil & 59,7 & 61,4 & 55,1 \\
Exatas e da terra & 55,4 & 52,6 & 39,5 \\
Biológicas & 70,5 & 73,9 & 67,6 \\
Engenharia/tecnologia & 15,3 & 22,4 & 18,0 \\
Ciências da saúde & 62,3 & 67,6 & 67,0 \\
Ciências agrárias & 27,2 & 38,7 & 43,5 \\
Ciências sociais aplicadas & 47,2 & 53,5 & 50,3 \\
Ciências humanas & 81,7 & 81,9 & 77,9 \\
Lingüística, letras, artes & 84,1 & 83,3 & 78,7 \\
\hline \hline
\end{tabular}

Fonte: MEC/INEP/SEEC 
Cristina Bruschini, Maria Rosa Lombardi

Tabela 7

Escolaridade feminina e masculina na População Economicamente Ativa (PEA) - Brasil

\begin{tabular}{|c|c|c|c|c|c|c|c|c|}
\hline \multirow{3}{*}{ Anos de Estudo } & \multicolumn{4}{|c|}{ Distribuição } & \multicolumn{4}{|c|}{ Taxas de Atividade } \\
\hline & \multicolumn{2}{|c|}{1993} & \multicolumn{2}{|c|}{1998} & \multicolumn{2}{|c|}{1993} & \multicolumn{2}{|c|}{1998} \\
\hline & $\mathrm{H}$ & $\mathrm{M}$ & $\mathrm{H}$ & $\mathrm{M}$ & $\mathrm{H}$ & $\mathrm{M}$ & $\mathrm{H}$ & $\mathrm{M}$ \\
\hline $\begin{array}{l}\text { s/ instrução e } \\
\text { menos de } 1 \text { ano }\end{array}$ & 17,0 & 14,4 & 14,1 & 10,6 & 74,4 & 40,2 & 72,4 & 36,6 \\
\hline 1 a 3 anos & 20,0 & 17,4 & 17,3 & 14,1 & 65,8 & 38,5 & 63,2 & 36,7 \\
\hline 4 a 7 anos & 34,1 & 32,0 & 32,8 & 29,6 & 75,5 & 43,4 & 70,1 & 41,8 \\
\hline 8 a 10 anos & 12,7 & 13,0 & 15,3 & 16,1 & 84,0 & 51,4 & 80,0 & 52,1 \\
\hline 11 a 14 anos & 11,6 & 16,9 & 14,9 & 21,7 & 89,5 & 68,2 & 86,5 & 69,6 \\
\hline 15 anos ou + & 4,5 & 6,0 & 5,3 & 7,5 & 91,3 & 81,4 & 90,2 & 81,0 \\
\hline Total \% & 100,0 & 100,0 & 100,0 & 100,0 & 76,0 & 47,0 & 71,2 & 47,5 \\
\hline Milhões & 42,9 & 28,0 & 45,6 & 31,3 & -- & -- & -- & -- \\
\hline
\end{tabular}

Fonte: FIBGE/PNAD.

Tabela 8

Distribuição de empregos e percentual de empregos femininos no setor formal, segundo nível de instrução - Brasil

\begin{tabular}{l|r|r|r|r}
\hline \hline \multirow{2}{*}{ Nível de instrução } & \multicolumn{3}{|c|}{ Distribuição dos empregos } & \multicolumn{2}{l}{$\begin{array}{l}\text { Parcela } \\
\text { feminina }\end{array}$} \\
\cline { 2 - 5 } & \multicolumn{1}{|c|}{ Total } & Masculino & Feminino & \\
\hline \hline 1988 & & & & \\
Até 8 & & & \\
$2^{\circ}$ grau (comple completa & 63,1 & 70,3 & 49,2 & 26,4 \\
Superior (compl e incompl) & 22,9 & 18,2 & 32,2 & 47,6 \\
Ignorado & 12,3 & 9,9 & 16,9 & 46,6 \\
Total \% & 1,7 & 1,8 & 1,7 & - \\
Milhões & 100,0 & 100,0 & 100,0 & 33,9 \\
\hline & 23.659 .727 & 15.641 .970 & 8.017 .757 & - \\
1998 & & & & \\
Até 8 série completa & 55,4 & 64,5 & 41,1 & 28,4 \\
$2^{\circ}$ grau (compl e incompl) & 29,2 & 23,9 & 37,8 & 49,7 \\
Superior (compl e incompl) & 15,3 & 11,7 & 21,1 & 52,9 \\
Ignorado & 0,1 & 0,1 & 0,1 & - \\
Total \% & 100,0 & 100,0 & 100 & 38,4 \\
Milhões & 24.491 .635 & 15.084 .796 & 9.406 .839 & - \\
\hline \hline
\end{tabular}

Fonte: MTE, RAIS. 
Instruídas e trabalhadeiras

Tabela 9

Distribuição dos ocupados por sexo e setor de atividade - Brasil

\begin{tabular}{l|r|r|r|r|r|r|r|r}
\hline \multirow{2}{*}{ Setor de atividade } & \multicolumn{2}{|c|}{1990} & \multicolumn{2}{|c|}{1993} & \multicolumn{2}{|c|}{1995} & \multicolumn{2}{|c|}{1998} \\
\cline { 3 - 8 } & $\mathrm{H}$ & $\mathrm{M}$ & $\mathrm{H}$ & $\mathrm{M}$ & $\mathrm{H}$ & $\mathrm{M}$ & $\mathrm{H}$ & $\mathrm{M}$ \\
\hline \hline Agropec., extração, & 28,1 & 14,0 & 29,6 & 24,3 & 28,4 & 22,5 & 26,0 & 19,3 \\
vegetal e pesca & & & & & & & & \\
Indústria & 29,1 & 13,7 & 27,2 & 10,1 & 26,4 & 9,3 & 27,0 & 9,6 \\
Comércio de & 12,3 & 12,2 & 13,1 & 12,0 & 13,3 & 12,8 & 13,3 & 13,7 \\
mercadorias & & & & & & & & \\
Prestação de serviços & 10,4 & 30,9 & 11,1 & 28,6 & 12,0 & 29,8 & 12,4 & 29,4 \\
Serviços auxiliares de & 3,3 & 3,0 & 3,2 & 2,3 & 3,5 & 2,9 & 4,2 & 3,3 \\
atividades econômicas & & & & & & & & \\
Social & 3,3 & 18,6 & 3,5 & 16,2 & 3,6 & 16,3 & 4,1 & 18,1 \\
Administração Pública & 5,1 & 4,0 & 5,2 & 3,9 & 5,1 & 3,9 & 5,1 & 3,9 \\
Transportes e & 5,2 & 1,0 & 5,2 & 0,8 & 5,6 & 0,8 & 5,9 & 1,0 \\
comunicação & & & & & & & & \\
Outros setores & 3,0 & 2,7 & 2,0 & 1,9 & 2,1 & 1,7 & 2,0 & 1,7 \\
Total \% & 10,0 & 100,0 & 100,0 & 100,0 & 100,0 & 100,0 & 100,0 & 100,0 \\
Milhões & 40,0 & 22,1 & 40,5 & 25,9 & 41,9 & 27,8 & 42,3 & 27,6 \\
\hline \hline
\end{tabular}

Fonte: FIBGE-PNADs, Banco de Dados sobre o Trabalho das Mulheres (FCC/SP)

Tabela 10

Distribuição dos ocupados por sexo e posição na ocupação - Brasil

\begin{tabular}{l|r|r|r|r|r|r}
\hline \hline \multirow{2}{*}{ Posição na ocupação } & \multicolumn{2}{|c|}{1993} & \multicolumn{2}{c|}{1995} & \multicolumn{2}{c}{1998} \\
\cline { 2 - 7 } & \multicolumn{1}{|c|}{$\mathrm{H}$} & \multicolumn{1}{|c}{ M } & \multicolumn{1}{c}{ M } & \multicolumn{1}{c}{$\mathrm{H}$} & \multicolumn{1}{c}{ M } \\
\hline \hline Empregados & 58,6 & 42,7 & 57,4 & 41,9 & 57,3 & 45,1 \\
Trabalhadores domésticos & 0,7 & 16,6 & 0,8 & 17,2 & 0,8 & 16,9 \\
Autônomos / contas próprias & 25,4 & 15,8 & 26,5 & 16,6 & 27,4 & 16,1 \\
Empregadores & 4,9 & 1,5 & 5,3 & 1,9 & 5,2 & 2,4 \\
Não remunerados & 8,6 & 13,5 & 8,0 & 13,1 & 7,1 & 11,4 \\
Consumo próprio *** & 1,9 & 9,9 & 1,9 & 9,3 & 2,2 & 8,1 \\
Trab.para próprio consumo & 1,6 & 9,8 & 1,6 & 9,0 & & \\
Trab. Na construção p/ uso próprio & 0,3 & 0,1 & 0,3 & 0,3 & & \\
Total ( \% ) & 100 & 100 & 100 & 100 & 100 & 100 \\
Milhões & 40,6 & 26,0 & 41,9 & 27,8 & 42,3 & 27,6 \\
\hline \hline
\end{tabular}

Fonte: FIBGE-PNADs 
Cristina Bruschini, Maria Rosa Lombardi

\section{Tabela 11}

Distribuição de homens e mulheres em posições precárias -

Brasil

\begin{tabular}{l|r|r}
\hline \hline Totais e alguns indicadores & 1993 & 1998 \\
\hline \hline Total de Homens em posições precárias & 11,2 & 10,1 \\
Total de Mulheres em posições precárias & 40,0 & 36,4 \\
Trabalhadoras domésticas & 16,6 & 16,9 \\
D não possuem carteira de trabalho & 83,9 & 76,4 \\
D ganham até 2 salários-mínimos & 96,5 & 88,5 \\
Não Remuneradas & 13,5 & 11,4 \\
Consumo próprio & 9,9 & 8,1 \\
\hline \hline Fonte: FIBGE, PNADs
\end{tabular}


Instruídas e trabalhadeiras

Tabela 12

Distribuição dos empregos segundo grandes grupos de ocupações e sexo Brasil

\begin{tabular}{|c|c|c|c|c|c|}
\hline \multirow[b]{2}{*}{ CBO* } & \multirow[b]{2}{*}{ Grandes Grupos de Ocupações } & \multicolumn{2}{|c|}{$1988 \%$} & \multicolumn{2}{|c|}{$1998 \%$} \\
\hline & & $\mathrm{H}$ & $\mathrm{M}$ & $\mathrm{H}$ & M \\
\hline GG 7 & $\begin{array}{l}\text { Trab. Indust., metalúrgica, siderúrgica, } \\
\text { madeira, papel e papelão, química, fiação e } \\
\text { tecelagem, alimentos e bebidas, mestres e } \\
\text { supervisores e trab. assem. }\end{array}$ & 7,1 & 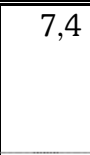 & 6,6 & 5,3 \\
\hline GG 9 & $\begin{array}{l}\text { Trab. Indust. Borracha, plástico, artes gráficas, } \\
\text { construção covil, operadores de máquinas e } \\
\text { assemelhados }\end{array}$ & 24,3 & 6,0 & 21,7 & 5,1 \\
\hline GG 8 & $\begin{array}{l}\text { Trab. Indust. Calçados, móveis, usinagem de } \\
\text { metais, ajustadores e montadores, eletricistas e } \\
\text { assemelhados }\end{array}$ & 10,9 & 3,1 & 9,8 & 1,9 \\
\hline GG 3 & $\begin{array}{l}\text { Trab. De serviços administrativos e } \\
\text { assemelhados }\end{array}$ & 17,7 & 29,7 & 17,5 & 30,5 \\
\hline GG 5 & $\begin{array}{l}\text { Trab. Serviços de turismo, hospitalidade, } \\
\text { serventia, hig. e embelez., seguran., aux. } \\
\text { Saúde e assem. }\end{array}$ & 9,6 & 12,0 & 14,2 & 20,0 \\
\hline GG 1 & $\begin{array}{l}\text { Juristas, professores, escritores, jornalistas, } \\
\text { escultores, pintores, músicos, artistas, técnicos } \\
\text { desportivos, atletas e trab. Assem. }\end{array}$ & 3,0 & 16,6 & 3,4 & 17,9 \\
\hline GG 4 & Trab. de comércio e trabalhadores e ass. & 6,1 & 6,6 & 8,0 & 8,8 \\
\hline GG 2 & $\begin{array}{l}\text { Membros do poder Legislativo, Executivo, } \\
\text { Judiciário, func. publ. sup., diret. Empresas e } \\
\text { assemelhados }\end{array}$ & 2,4 & 3,2 & 3,6 & 4,5 \\
\hline GG 0 & $\begin{array}{l}\text { Químicos, físicos, engenheiros, arquitetos, } \\
\text { técnicos, bologistas, farmacêuticos, } \\
\text { enfermeiros, psicólogos, estatísticos, } \\
\text { economistas, administ, contadores e ass. }\end{array}$ & 6,1 & 7,3 & 5,0 & 4,5 \\
\hline GG 6 & $\begin{array}{l}\text { Trab. Agropecuários, florestais, da pesca e } \\
\text { assemelhados }\end{array}$ & 4,2 & 1,1 & 5,9 & 1,0 \\
\hline & Ocupação ignorada ou mal definida & 8,6 & 7,0 & 4,3 & 0,6 \\
\hline & Total & 100,0 & 100,0 & 100,0 & 100,0 \\
\hline
\end{tabular}

Fonte: MTE/ RAIS

*CBO/Classificação Brasileira de Ocupações 
Cristina Bruschini, Maria Rosa Lombardi

Tabela 13

Distribuição dos ocupados por sexo $e$ faixas de rendimento - Brasil

\begin{tabular}{r|r|r|r|r|r|r|r|r}
\hline \hline $\begin{array}{l}\text { Classes de } \\
\text { rendimento mensal } \\
\text { (em salários }\end{array}$ & \multicolumn{2}{|c|}{1990} & \multicolumn{2}{c|}{1993} & \multicolumn{2}{c|}{1995} & \multicolumn{2}{c}{1998} \\
\cline { 2 - 8 } mínimos) & $\mathrm{H}$ & $\mathrm{M}$ & $\mathrm{H}$ & $\mathrm{M}$ & $\mathrm{H}$ & $\mathrm{M}$ & $\mathrm{H}$ & $\mathrm{M}$ \\
\hline \hline Até 1 s.m & 19,9 & 33,3 & 25,5 & 35,7 & 19,0 & 28,2 & 18,4 & 25,8 \\
De 1 a 2 s.m & 20,3 & 20,8 & 22,3 & 18,9 & 21,0 & 19,7 & 20,7 & 21,0 \\
De 2 a 5 s.m & 29,3 & 21,9 & 25,1 & 14,3 & 28,1 & 18,5 & 29,7 & 21,3 \\
Mais de 5 s.m & 22,8 & 12,5 & 15,0 & 6,4 & 20,3 & 10,1 & 19,6 & 11,0 \\
Sem rendimento & 7,0 & 11,0 & 10,9 & 23,8 & 10,3 & 22,7 & 10,0 & 19,9 \\
Total ( \% ) & 100,0 & 100,0 & 100,0 & 100,0 & 100,0 & 100,0 & 100,0 & 100,0 \\
Milhões & 40,0 & 22,1 & 40,5 & 25,9 & 41,9 & 27,8 & 42,3 & 27,6 \\
\hline \hline
\end{tabular}

Fonte: FIBGE, PNADs 
Instruídas e trabalhadeiras

Tabela 14

Rendimento dos ocupados segundo o sexo, setores de atividade selecionados, jornada de trabalho e escolaridade de nível superior - Brasil

\begin{tabular}{|c|c|c|c|c|c|c|c|c|c|c|c|c|}
\hline \multirow{3}{*}{$\begin{array}{l}\text { Classes de } \\
\text { rendimento mensal }\end{array}$} & \multicolumn{8}{|c|}{ Setores de atividade selecionados } & \multirow{2}{*}{\multicolumn{2}{|c|}{$\begin{array}{l}\text { Jornada de } \\
\text { trabalho } \\
\text { período } \\
\text { integral* }\end{array}$}} & \multirow{2}{*}{\multicolumn{2}{|c|}{$\begin{array}{l}\text { Escolaridade } \\
\text { superior ** }\end{array}$}} \\
\hline & \multicolumn{4}{|c|}{1995} & \multicolumn{4}{|c|}{1998} & & & & \\
\hline & Agrícola & Indústria & $\begin{array}{c}\text { Prest. } \\
\text { Serviços }\end{array}$ & Social & Agrícola & Indústria & $\begin{array}{c}\text { Prest. } \\
\text { Serviços }\end{array}$ & Social & 1993 & 1998 & 1993 & 1998 \\
\hline $\begin{array}{l}\text { HOMENS } \\
\text { até } 2 \text { SM }\end{array}$ & 55,0 & 33,4 & 42,5 & 28,9 & 53,9 & 36,6 & 40,6 & 26,3 & 48,0 & 38,0 & 4,2 & 2,6 \\
\hline Mais de 2 a $5 \mathrm{SM}$ & 11,2 & 38,4 & 34,1 & 28,5 & 10,6 & 39,8 & 37,6 & 31,6 & 27,2 & 32,5 & 14,7 & 8,4 \\
\hline Mais de 5 SM & 4,3 & 23,4 & 17,7 & 39,0 & 3,6 & 19,5 & 16,4 & 38,3 & 17,7 & 22,9 & 76,9 & 84,6 \\
\hline Sem rendimento & 27,9 & 3,0 & 4,8 & 2,3 & 30,0 & 2,9 & 3,9 & 2,4 & 5,9 & 5,0 & 0,9 & 0,9 \\
\hline $\begin{array}{r}\text { Total } * * * \\
\text { MULHERES }\end{array}$ & 100 & 100 & 100 & 100 & 100 & 100 & 100 & 100 & 100 & 100 & 100 & 100 \\
\hline até $2 \mathrm{SM}$ & 16,0 & 49,1 & 77,9 & 45,2 & 16,9 & 49,2 & 75,8 & 40,7 & 56,3 & 43,8 & 12,3 & 5,5 \\
\hline Mais de 2 a $5 \mathrm{SM}$ & 1,2 & 30,7 & 13,7 & 32,8 & 1,1 & 31,0 & 16,1 & 34,3 & 23,7 & 31,3 & 32,2 & 22,6 \\
\hline Mais de $5 \mathrm{SM}$ & 0,3 & 12,0 & 3,3 & 19,7 & 0,2 & 12,6 & 3,0 & 21,8 & 11,5 & 18,2 & 51,4 & 67,5 \\
\hline Sem rendimento & 81,9 & 7,2 & 4,5 & 1,5 & 81,3 & 6,1 & 4,1 & 2,3 & 7,7 & 5,6 & 1,8 & 2,2 \\
\hline Total $* * *$ & 100 & 100 & 100 & 100 & 100 & 100 & 100 & 100 & 100 & 100 & 100 & 100 \\
\hline $\begin{array}{c}\text { Fonte: FIBGE- PNADs } \\
* \text { * de } 40 \text { a } 44 \text { horas } \\
* * * \text { incluso sem declarac }\end{array}$ & studo & & & & & & & & & & & \\
\hline
\end{tabular}

